\title{
Epstein-Barr Virus-specific Cytotoxic T Cell Responses in HIV-1 Infection Different Kinetics in Patients Progressing to Opportunistic Infection or Non-Hodgkin's Lymphoma
}

\author{
Marie José Kersten, ${ }^{\star \ddagger}$ Michèl R. Klein, ${ }^{\ddagger}$ Agnes M. Holwerda, ${ }^{\ddagger}$ Frank Miedema, ${ }^{\ddagger \S}$ and Marinus H.J. van Oers ${ }^{\star}$ \\ $*$ Department of Hematology, Academic Medical Center, and ${ }^{\ddagger}$ Department of Clinical Viro-immunology, Central Laboratory of the \\ Netherlands Red Cross Blood Transfusion Service/Laboratory of Experimental and Clinical Immunology, University of Amsterdam, \\ 1105 AZ Amsterdam, The Netherlands; and ${ }^{\S}$ Department of Human Retrovirology, Academic Medical Center, 1105 AZ Amsterdam, \\ The Netherlands
}

\begin{abstract}
Although the high incidence of EBV-associated diffuse large cell lymphomas (DLCL) in HIV-1 infection is believed to be related to loss of immune control due to HIV-induced immune deficiency, it has been claimed that cytotoxic $\mathrm{T}$ lymphocyte (CTL) responses to EBV are longer lasting in HIV-1-infected persons than CTL directed against HIV-1 itself. We approached this apparent paradox by performing the first longitudinal study into the kinetics of EBV and $\mathrm{HIV}$-specific CTL responses in HIV-infected patients progressing either to AIDS with non-Hodgkin's lymphoma (NHL) or AIDS with opportunistic infection (OI). Multiple samples were tested from HIV-1 seroconversion to AIDS-diagnosis.

Four out of six patients that were either long-term asymptomatic or progressing to OI showed declining HIV-1 CTL precursor (CTLp) frequencies whereas EBV-CTLp remained stable, suggestive for HIV-1-specific immune exhaustion. In two patients rapidly progressing to AIDS-OI, a parallel decline of HIV-1- and EBV-CTL responses was seen, indicative for total collapse of cellular immunity. In all these six patients EBV-load remained low. However, in four out of five patients that progressed to DLCL, EBV-load was high and increasing several months preceding the NHL. In all five patients, EBVCTLp decreased before the emergence of the NHL.

Thus, our data show that in HIV-1 infection loss of HIV1-specific $T$ cell immunity is not necessarily paralleled by loss of EBV-specific T cell responses. The occurrence of AIDS-related DLCL is preceded by decreasing EBV-CTLp and increasing EBV load. Failing EBV-control might therefore be an important step in the pathogenesis of AIDSrelated DLCL. (J. Clin. Invest. 1997. 99:1525-1533.) Key words: HIV-1 infection - EBV-specific cytotoxic T cells • HIV-1-specific cytotoxic T cells • non-Hodgkin's lymphoma
\end{abstract}

\section{Introduction}

EBV is a ubiquitous human herpes virus, affecting more than $90 \%$ of the world population (1). After primary EBV infection, which usually occurs in early childhood and is often asymp-

Address correspondence to M.H.J. van Oers, Department of Hematology, F4-224, Academic Medical Center, Meibergdreef 9, 1105 AZ Amsterdam. Phone: 31-205665785; FAX: 31-206919743.

Received for publication 7 October 1996 and accepted in revised form 21 January 1997.

J. Clin. Invest.

(C) The American Society for Clinical Investigation, Inc.

0021-9738/97/04/1525/09 \$2.00

Volume 99, Number 7, April 1997, 1525-1533 tomatic, the virus is known to persist lifelong in the B lymphocytes. The immune response to EBV infection is mediated initially by natural killer cells and $\mathrm{CD}^{+}{ }^{+} \mathrm{T}$ lymphocytes. Later in infection, EBV-specific $\mathrm{CD}^{+} \mathrm{MHC}$ class I-restricted cytotoxic $\mathrm{T}$ lymphocytes (CTL) ${ }^{1}$ emerge and are considered to be responsible for immunologic control of the pool of latently infected B cells (2). The antibody response is thought to be of less significance. Immunodeficiency, either congenital (e.g., $\mathrm{X}$-linked lymphoproliferative disease) or acquired (e.g., posttransplant immunosuppression or in HIV-1 infection) can lead to reactivation of EBV-infection and uncontrolled lymphoproliferation $(3,4)$.

In HIV-1 infected patients EBV is associated with oral hairy leukoplakia, with the majority of AIDS-related diffuse large cell non-Hodgkin's lymphomas (NHL; 5), with Hodgkin's disease, and with smooth-muscle tumors (6). Approximately $75 \%$ of these NHL and virtually all primary central nervous system NHL in patients with AIDS are EBV-positive by in situ hybridization for EBER (Epstein-Barr virus small RNAs). AIDS-related Burkitt-type NHL, on the contrary, resemble sporadic and not endemic Burkitt lymphoma, in that they are often EBV-negative (7).

Although EBV-specific CTL are known to play a key role in EBV-specific immunity in healthy individuals, the mechanism of the presumedly defective EBV-immunosurveillance in HIV-1 infection is largely unknown. In vitro, defective regulation of EBV infection in patients with AIDS has been demonstrated by Birx et al. T cells from patients with AIDS are unable to suppress outgrowth of autologous EBV-infected B cells, possibly explaining the abnormally high numbers of EBV-infected B cells present in the peripheral blood of these patients (8). Thus far, there have been few and only cross-sectional studies concerning EBV-specific $\mathrm{T}$ cell responses in HIV-1 infection. Whereas Blumberg et al. found severely decreased EBV-specific cytotoxic T cell activity in patients with AIDS and AIDS-related complex (9), studies by Carmichael et al. (10), and Geretti et al. (11) comparing EBV- to HIV-specific $\mathrm{T}$ cell responses seemed to show preservation of EBVspecific CTL in advanced HIV-1 infection, suggesting selective loss of HIV-1-specific CTL. Previously, in a longitudinal study, we have shown persistence of HIV-1-specific CTL associated with low viral load in long-term asymptomatically (LTA) HIV-1 infected individuals, whereas in rapid progressors to AIDS the number of productively HIV-1 infected cells

1. Abbreviations used in this paper: $\mathrm{B}-\mathrm{LCL}, \mathrm{B}-\mathrm{lymphoblastoid} \mathrm{cell}$ lines; CTL, cytotoxic T lymphocyte; CTL(p), cytotoxic T lymphocyte (precursor); EBNA, Epstein-Barr virus nuclear antigen; LTA, long-term asymptomatic; NHL, non-Hodgkin's lymphoma; OI, opportunistic infection; PHA, phytohemagglutinin; rIL-2, recombinant interleukin-2; rVV, recombinant Vaccinia virus; TCID, tissue culture infectious dose. 
increased and HIV-1-specific CTL were lost (12). Using the unique patient material generated by the Amsterdam Cohort Studies on AIDS, we were able to perform the first longitudinal study in which EBV-specific $\mathrm{CTL}_{\mathrm{p}}$ frequencies and $\mathrm{EBV}$ load were measured in HIV-1-seropositive subjects, starting at or soon after HIV-seroconversion and measuring up to AIDSdiagnosis. This study was aimed at two major questions: $(a)$ is there evidence for differential regulation of EBV- and HIV1-specific T cell responses in HIV-1 infection, causing selective loss of HIV-1-specific CTL; and (b) if EBV-specific T cell responses diminish and EBV load increases in HIV-1 infection, is this associated with the occurrence of diffuse large cell NHL?

\section{Methods}

Patients. Patients are participants of the Amsterdam Cohort Studies on AIDS. These individuals at risk for HIV-1-infection visited the Municipal Health Services at three-month intervals, when a medical history and physical examination were carried out, and blood samples were collected for HIV-1 serology and immunological studies. In addition, at all time points PBMC were cryopreserved. For this study, we analyzed two HIV-1-seropositive LTA individuals (L120 and L206) with $\mathrm{CD}^{+} \mathrm{T}$ cell counts $>500 / \mathrm{mm}^{3}$ during more than $8 \mathrm{yr}$ of asymptomatic follow-up and four cohort participants (P159, P186, $\mathrm{P} 224$, and P450) who progressed to AIDS (classification of the Centers for Disease Control 1993) within 6 yr (median 54 mo) after seroconversion. Furthermore, five HIV-1 infected patients with diffuse large cell NHL were studied (N 219, N308, N319, N568, and N6006) as well as two patients with AIDS-related Burkitt-type NHL (B218 and B481). L120, L206, N219, and B218 are noncohort participants monitored at the Academic Medical Center. Clinical and laboratory data of the patients are shown in Table I. Healthy controls were five HIV-1-seronegative but EBV-seropositive blood bank donors.
Results on HIV-1-specific CTL responses in patients L206, P159, P186, P224, and P450 have been reported earlier (12).

Immunological parameters. $\mathrm{T}$ lymphocyte immunophenotyping for $\mathrm{CD} 4$ and $\mathrm{CD} 8$ membrane markers was done in real time by flow cytofluorometry. Polyclonal T cell proliferation was assessed both by real time measurement of the CD3-monoclonal antibody $(\mathrm{mAb})$ (CLB-T3/4E; Central Laboratory of the Netherlands Red Cross Blood Transfusion Service, Amsterdam, The Netherlands) and phytohemagglutinin (PHA)-induced proliferative capacity of PBMC in whole-blood cultures (13), as well as by measurement of the PHAinduced proliferative capacity of the cryopreserved PBMC used in the CTL experiments (data not shown).

Recombinant vaccinia viruses $(r V V)$. The $\mathrm{rVV}$ used in these studies were constructed from the Copenhagen strain of Vaccinia virus, and include rVV TG.1144 expressing Gag of HIV-1 LAI $_{\text {(14), and }}$ control-rVV 186-poly containing no insert; kindly provided by Dr. Y. Rivière (Institut Pasteur, Paris, France) and Dr. M.P. Kieny (Transgène S.A., Strassbourg, France). The rVV containing the EBV latent proteins Epstein-Barr virus nuclear antigen (EBNA)-3A, 3B, and 3C were kindly provided by Dr. A.B. Rickinson (Cancer Research Campaign, Birmingham, UK).

Induction of HIV-1 and EBV-specific CTL responses. From all subjects, EBV-transformed lymphoblastoid B cell lines (B-LCL) were generated using B95.8 virus. HIV-1 and EBV-specific CTL were expanded in vitro by antigen-specific stimulation as previously described $(12,15)$. Frequencies of Gag- and EBV-specific precursor CTL (CTLp) were determined using standard methods of limiting dilution analysis (16). Briefly, PBMC isolated by Ficoll-Hypaque gradient and cryopreserved at different time points during the study were thawed and resuspended in RPMI 1640 (Gibco, Grand Island, NY) supplemented with L-glutamine, penicillin, streptomycin, and $10 \%$ pooled human serum. Viability of the thawed cells was tested using trypan-blue dye-exclusion. The percentage of dead cells in all experiments varied between 5 and $20 \%$, but was usually lower than $10 \%$. For each patient, cell samples from all six time points were tested si-

Table I. Clinical and Laboratory Data of Long-Term Asymptomatic Individuals (LTA), Progressors to AIDS (PROG), Patients with Diffuse Large Cell NHL, and Patients with Burkitt-type NHL

\begin{tabular}{|c|c|c|c|c|c|c|c|}
\hline Subjects & Age* & HLA class $I^{\ddagger}$ & $\begin{array}{l}\text { Seroconversion } \\
\text { status }^{\S}\end{array}$ & $\begin{array}{c}\text { Virus } \\
\text { phenotype }\end{array}$ & $\begin{array}{c}\text { AIDS } \\
\text { diagnosis }^{\mathbb{I}}\end{array}$ & $\mathrm{CD} 4 * *$ & Follow-up \\
\hline \multicolumn{8}{|l|}{ LTA } \\
\hline L120 & 25 & $\mathrm{~A} 1,2 ; \mathrm{B} 13$ & II & NSI & NA & 0.6 & $>128$ \\
\hline L206 & 32 & $\mathrm{~A} 3,25 ; \mathrm{B} 18,51$ & II & NSI & NA & 1.17 & $>135$ \\
\hline \multicolumn{8}{|l|}{ PROG } \\
\hline $\mathrm{P} 159$ & 46 & $\mathrm{~A} 1 ; \mathrm{B} 8 ; \mathrm{Cw} 7$ & I & SI (18) & $\mathrm{PCP}, \mathrm{CAO}$ & 0.08 & 32 \\
\hline $\mathrm{P} 186$ & 30 & $\mathrm{~A} 3,24 ; \mathrm{B} 60 ; \mathrm{Cw} 3,4$ & I & NSI & PCP & 0.06 & 42 \\
\hline $\mathrm{P} 224$ & 28 & A3;B44,51;Cw4,7 & I & SI (45) & PCP & 0.15 & 60 \\
\hline $\mathrm{P} 450$ & 29 & $\mathrm{~A} 24,28 ; \mathrm{B} 39,44$ & I & SI (52) & KS & 0.07 & 65 \\
\hline \multicolumn{8}{|l|}{ NHL } \\
\hline N219 & 27 & $\mathrm{~A} 1,9 ; \mathrm{B} 7,8$ & II & $\mathrm{nt}$ & $\mathrm{CAO}$ & 0.39 & 36 \\
\hline N308 & 42 & $\mathrm{~A} 1 ; \mathrm{B} 8,51 ; \mathrm{Cw} 7$ & II & NSI & NHL & 0.07 & 91 \\
\hline N319 & 39 & $\mathrm{~A} 2,28 ; \mathrm{B} 8,60$ & II & NSI & NHL & 0.3 & 44 \\
\hline N568 & 41 & $\mathrm{~A} 2,3 ; \mathrm{B} 7,51 ; \mathrm{Cw} 7$ & II & SI (40) & NHL & 0.07 & 52 \\
\hline N6006 & 48 & $\mathrm{~A} 2,32 ; \mathrm{B} 7,35$ & II & NSI & NHL & 0.1 & 69 \\
\hline \multicolumn{8}{|l|}{ Burkitt } \\
\hline B218 & 48 & A2;B35;Cw4 & II & $\mathrm{nt}$ & NHL & 1.11 & 59 \\
\hline B481 & 30 & A11,26;B7,51;Cw3,7 & II & $\mathrm{nt}$ & NHL & 0.46 & 39 \\
\hline
\end{tabular}

*Age (year) at HIV-1 seroconversion or first seropositive visit. ${ }^{*} \mathrm{HLA}$ class I typing was performed at the Department of Transplantation Immunology, CLB, Amsterdam, The Netherlands using standard serological typing methods. ${ }^{\S}$ Known date of HIV-1 seroconversion (I) or seropositive upon entry in the cohort study (II). "Syncytium-inducing (SI; months after seroconversion) or nonsyncytium-inducing (NSI); tested in an MT2-assay.nt, not tested. "AIDS diagnosis: NA, not applicable for LTA; PCP, Pneumocystis carinii pneunomia; CAO, Candida albicans oesophagitis; KS, Kaposi's sarcoma; NHL, non-Hodgkin's lymphoma. **CD4: CD4 ${ }^{+}$T cell numbers at AIDS-diagnosis or October 1995 for LTA. ${ }^{*}$ Follow-up: time (months) between seroconversion or seropositive entry and AIDS-diagnosis for progressors; NHL diagnosis for NHL patients, or October 1995 for LTA. 
multaneously. Eight serial dilutions of PBMC ranging from 20,000 to 745 cells/well were seeded 24-fold in 96-well round-bottom microtiter plates (Costar Corp., Cambridge, MA). To each well $10^{4}$ autologous PBMC (30 Gy irradiated) were added as feeder cells. For HIV-1 specific CTL, stimulator cells were $10^{4}$ autologous EBV-transformed B-LCL infected with rVV-TG.1144 and subsequently inactivated with paraformaldehyde. For EBV-specific CTL, $10^{4}$ irradiated (50 Gy) autologous EBV-transformed B-LCL were used as stimulator cells. At day 2 and 9 cultures were fed with medium containing recombinant IL-2 (rIL-2) (Proleukin, kindly provided by Dr. R. Rombouts, Chiron Benelux BV, Amsterdam, The Netherlands), and at day 7 they were restimulated with either B-LCL infected with rVV-TG.1144 (Gag) for HIV-1-specific CTL; or irradiated autologous B-LCL for EBV-specific CTL. On day 15, wells were split and effector cells were tested for cytotoxicity.
Cytotoxicity assays. Standard ${ }^{51} \mathrm{Cr}$ release assays were performed as previously described (15). For HIV-1 CTL the targets were autologous B-LCL infected with 5 MOI rVV-TG.1144 expressing the Gagprotein, or rVV 186-poly as control targets. For EBV-specific CTL four different targets were used: the autologous B-LCL and an HLAmismatched B-LCL as control for HLA-restriction and specificity $(17,10)$; in addition, to increase sensitivity of the assay, autologous B-LCL superinfected with rVV-EBNA 3A, 3B, and 3C (thus overexpressing the immunodominant EBV-latent proteins) or with $\mathrm{rVV}^{-\mathrm{TK}^{-}}$ containing no insert were used. In preliminary experiments using FACS $^{\circledR}$ analysis, infection of B-LCL with rVV-3A, 3B, and 3C was shown to increase the mean fluorescence intensity of these antigens (data not shown). Target cells were labeled with $100 \mu \mathrm{Ci} \mathrm{Na}{ }_{2}^{51} \mathrm{CrO}_{4}$ (Amersham International, Little Chalfont, UK) for $16 \mathrm{~h}$. After three washings, $4 \times 10^{3}$ target cells were added to each well. After $4 \mathrm{~h}$ of in-

A

B
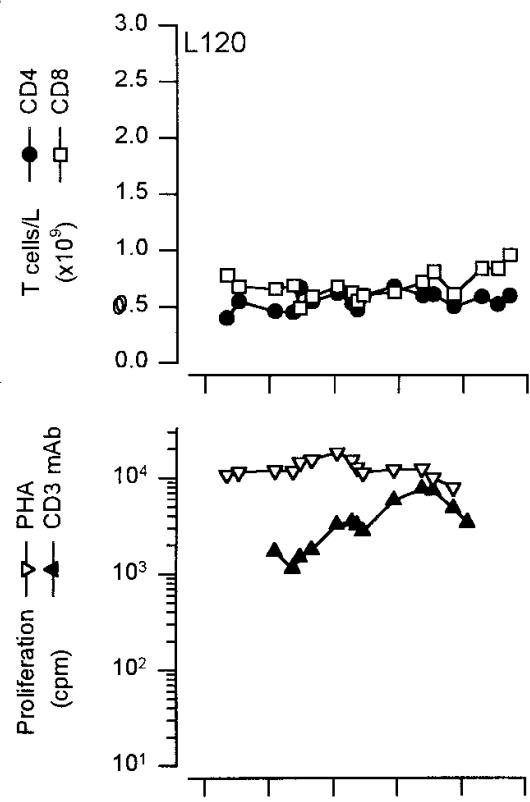

C
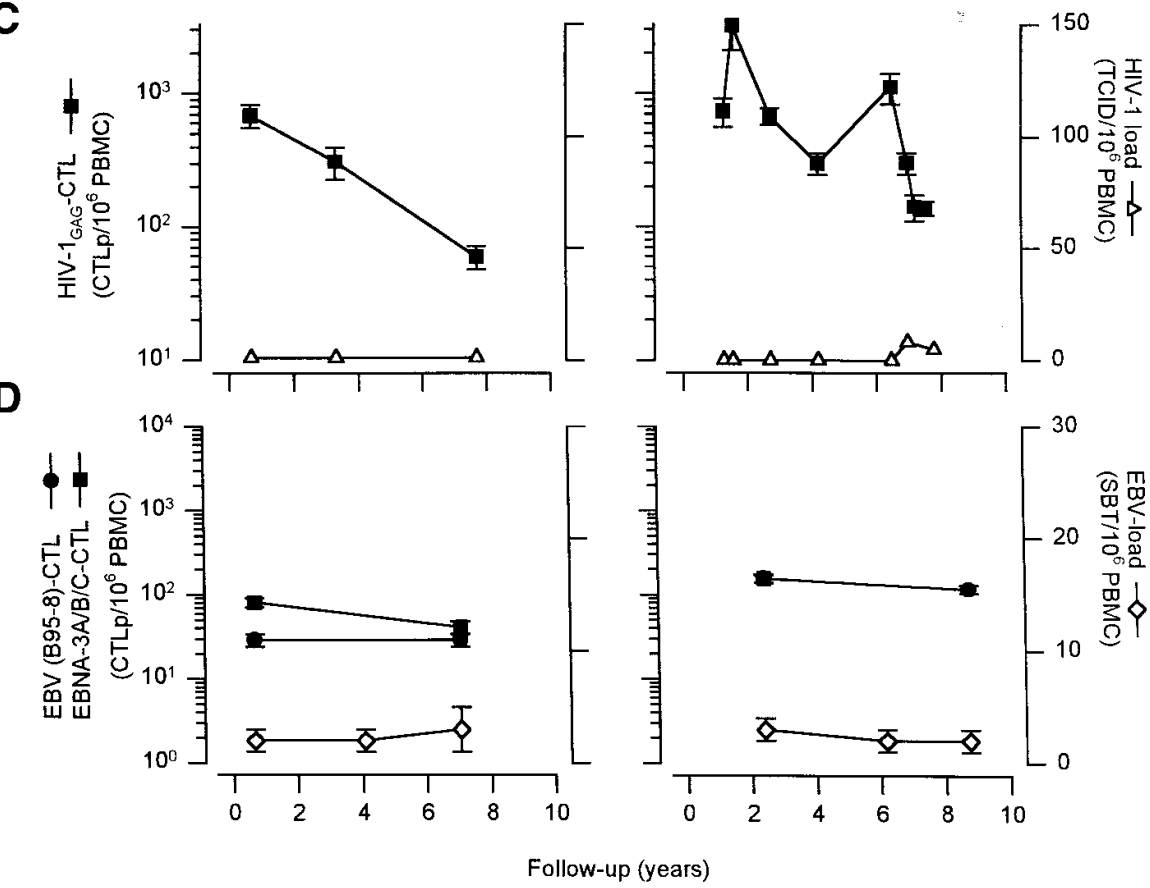
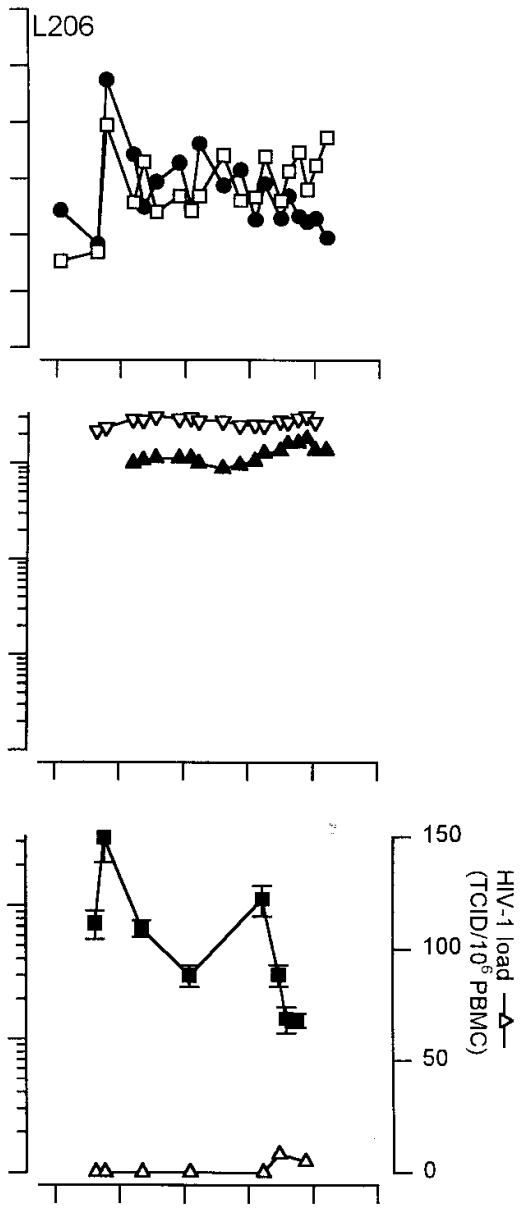

क़⿱ m) $\frac{1}{\circ}$ two different targets. (O) EBV-specific CTLp frequency using B95-8 transformed autologous B-LCL, expressed as number of CTLp per $10^{6}$ PBMC; ( $\left.\mathbf{\square}\right)$ EBV-specific CTLp frequency using autologous B-LCL superinfected with rVV EBNA $3 \mathrm{~A} / \mathrm{B} / \mathrm{C}$ as targets (left axis). The EBV load $(\diamond)$ was estimated with a spontaneous B cell transformation assay (number of EBV-positive $\mathrm{B}$ cells per $10^{6} \mathrm{PBMC}$; right axis).

Figure 1. Comparison of HIV-1 and EBVspecific cytotoxic $\mathrm{T}$ lymphocyte response status in two long-term asymptomatic HIV-1-seropositive subjects. On the $x$-axis follow-up is indicated in years after HIV-1 seropositive entry in the study. $(A)$ Longitudinal analysis of CD4 (๑) and CD8 ( $\square$ ) T lymphocyte subsets. Normal values (90\% CI: for CD4, 0.56-1.55; for CD8, $0.31-1.00 \times 10^{9} /$ liter) were determined in a group of $430 \mathrm{HIV}-1$ seronegative volunteers. $(B)$ Longitudinal analysis of the CD3 MAb- $(\boldsymbol{\Delta})$ and PHA $(\nabla)$-induced ceactivity of PBMC measured in rea using $\left[{ }^{3} \mathrm{H}\right]$ thymidine incorporation (expressed as counts per minute [cpm]. $(C)$ Longitudinal analysis of HIV-1 Gag-specific CTLp frequency ( $\mathbf{\square})$ analyzed in cryopreserved blood samples (expressed as number of CTLp per $10^{6} \mathrm{PBMC} \pm \mathrm{SEM}$; left axis). Antigen-specific CTL were cultured in limiting dilution and tested in a ${ }^{51} \mathrm{Cr}$ release assay (see Methods). The $\mathrm{HIV}$-load $(\triangle)$ is expressed as tissue culture infectious dose (TCID $/ 10^{6} \mathrm{CD} 4^{+} \mathrm{T}$ cells), representing the proportion of $\mathrm{CD}_{4}^{+} \mathrm{T}$ (right axis). (D) Longitudinal analysis of the EBV-specific $T$ cell response, using cells productively infected with HIV-1 
cubation at $37^{\circ} \mathrm{C}$, supernatants were harvested and radioactivity was counted with a gamma-counter (model Cobra II; Packard Instrument Co., Meriden, CT). Spontaneous ${ }^{51} \mathrm{Cr}$ release was always $<15 \%$ of maximum release. Specific lysis was calculated with the formula: $100 \times([$ experimental release - spontaneous release]/[maximum release - spontaneous release]). Wells were considered positive when ${ }^{51} \mathrm{Cr}$ release exceeded $10 \%$ specific lysis. Statistical analysis was performed using methods described by Strijbosch et al. (18). CTLp frequencies are expressed as number of CTLp $/ 10^{6}$ PBMC. Gag-specific CTLp frequencies were computed as differences between CTLp frequencies determined on Gag-expressing versus control targets. The average CTLp-frequency on control targets both for HIV-1- and EBV-specific CTL was $<25 / 10^{6}$ PBMC.

Comparison of EBV-specific CTLp frequencies using $B-L C L$ or $r V V$ EBNA $3 A / B / C$-infected $B$ - $L C L$ as targets. The sensitivity of the
EBV-CTLp assay was increased up to 10-fold without loss of specificity by using as target cells B-LCL infected with rVV expressing the immunodominant EBV-latent antigens (EBNA 3A/B/C). CTLp frequencies found with B-LCL or rVV EBNA $3 \mathrm{~A} / \mathrm{B} / \mathrm{C}$ infected B-LCL as targets did however follow the same kinetic pattern. Only in subject L206 no increase in CTLp frequency was found. In patient N308 the CTLp frequency found with $\mathrm{rVV}$ EBNA $3 \mathrm{~A} / \mathrm{B} / \mathrm{C}$ superinfected B-LCL as target cells was even lower than that found using B-LCL alone. This suggests that in these two subjects another epitope is recognized, located for example in the latent membrane protein (LMP)1 (19).

$H I V-1$ cellular load. The proportion of $\mathrm{CD}^{+} \mathrm{T}$ cells productively infected with HIV-1 was determined using clonal virus isolation procedures as previously described (20). Briefly, 12.500-25.000 PBMC of HIV-1-infected patients were cocultivated with $10^{5} 2$-d PHA-stimulated PBMC from HIV-1 seronegative blood donors.

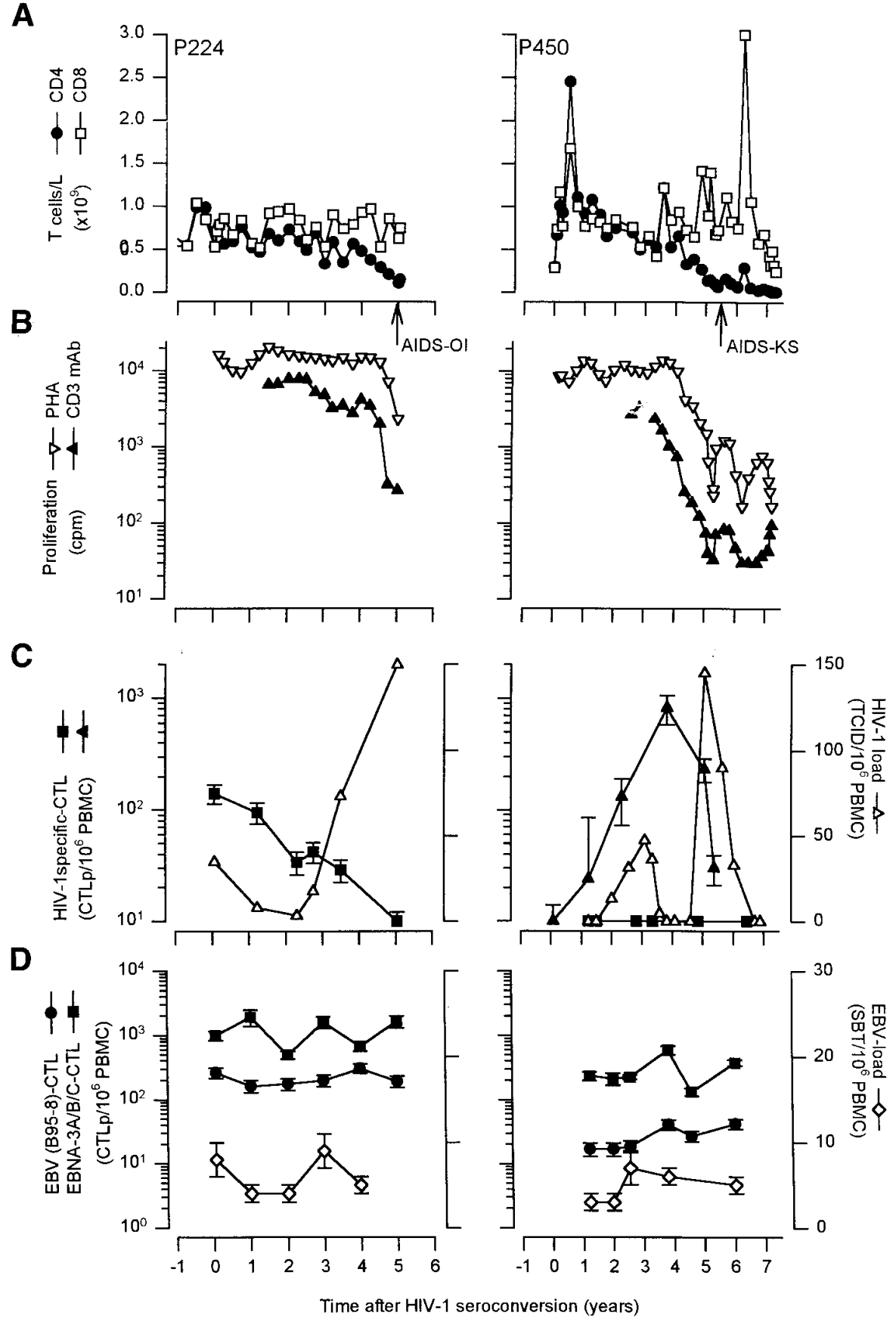

Figure 2. Comparison of HIV-1 and EBV-specific cytotoxic T lymphocyte responses and viral load in comparison to immune status in two typical progressors to AIDS-opportunistic infection. On the $x$-axis follow up is indicated in years after HIV-1 seroconversion. ( $A$ ) Longitudinal analysis of CD4 (๑) and CD8 ( $\square$ ) T lymphocyte subsets. The arrow indicates the time of AIDS-diagnosis. (B) Longitudinal analysis of the CD3 MAb- $(\boldsymbol{\Delta})$ and PHA $(\nabla)$-induced $\mathrm{T}$ cell reactivity of PBMC measured in real time by a whole blood proliferation assay using $\left[{ }^{3} \mathrm{H}\right]$ thymidine incorporation (expressed as counts per minute $[\mathrm{cpm}] .(C)$ Longitudinal analysis of HIV-1 Gag (ם) and RT ( $(\boldsymbol{\Delta})$ specific CTLp frequency analyzed in cryopreserved blood samples (expressed as number of CTLp per $10^{6} \mathrm{PBMC} \pm \mathrm{SEM}$; left axis). Antigenspecific CTL (either Gag or RT) were cultured in limiting dilution and tested in a

${ }^{51} \mathrm{Cr}$ release assay. The HIV-load $(\triangle)$ is expressed as tissue culture infectious dose (TCID $/ 10^{6} \mathrm{CD}^{+} \mathrm{T}$ cells), representing the proportion of $\mathrm{CD}^{+} \mathrm{T}$ cells productively infected with HIV-1 (right axis). (D) Longitudinal analysis of the EBV-specific $\mathrm{T}$ cell response, using two different targets. (-) EBV-specific CTLp frequency using B95-8 transformed autologous B-LCL, expressed as number of CTLp per $10^{6}$ PBMC; (匹) EBV-specific CTLp frequency using autologous B-LCL superinfected with $\mathrm{rVV}$ EBNA $3 \mathrm{~A} / \mathrm{B} / \mathrm{C}$ as targets (left axis). The EBV load $(\diamond)$ was estimated with a spontaneous B cell transformation assay (number of EBV-positive B cells per $10^{6}$ PBMC; right axis). 
HIV-1 replication was monitored weekly by screening culture supernatants for p24 production using a p24-capture ELISA. Statistical analysis of positive wells was performed as described by Strijbosch et al. (18). Viral load was expressed as tissue culture infectious dose (TCID) $/ 10^{6} \mathrm{CD}^{+} \mathrm{T}$ cells).

EBV load. EBV load was estimated with a spontaneous B cell transformation assay as previously described $(21,22)$. Briefly, PBMC were thawed, resuspended in RPMI 1640 supplemented with L-glutamine, antibiotics, 10\% FCS (Hyclone, Logan, Utah) and Cyclosporin A (final concentration $1 \mu \mathrm{g} /$ liter; Sandoz Ltd., Basel, Switzerland) and cultured in limiting dilution at six serial dilutions with concentrations ranging from 1 or $0.5 \times 10^{6}$ to $1.5 \times 10^{4}$ cells/well (six replicate cultures per dilution) in 96-well microtiter plates. Cells were fed weekly with RPMI $10 \%$ FCS and monitored microscopically for the outgrowth of EBV-transformed B lymphocytes (large transformed cells and growing clusters of cells). Results were calculated using the method of Strijbosch et al. (18), and expressed as EBV-infected B cells $/ 10^{6}$ PBMC. For comparison of EBV load in different patient groups an unpaired Student's $t$ test was used.

\section{Results}

Temporal relationship of $H I V-1-$ and $E B V$-specific CTL responses

Long-term asymptomatic HIV-1 infected individuals. In the two LTA (L206 and L120) $\mathrm{CD}^{+} \mathrm{T}$ cell counts and polyclonal $\mathrm{T}$ cell function remained within the normal range at least $8 \mathrm{yr}$ after seroconversion (Fig. $1 A$ and $B$ ). Although HIV-1-specific CTLp frequencies declined gradually over time, they were still in the range of $100 / 10^{6}$ PBMC. HIV-1 load was undetectable or

A

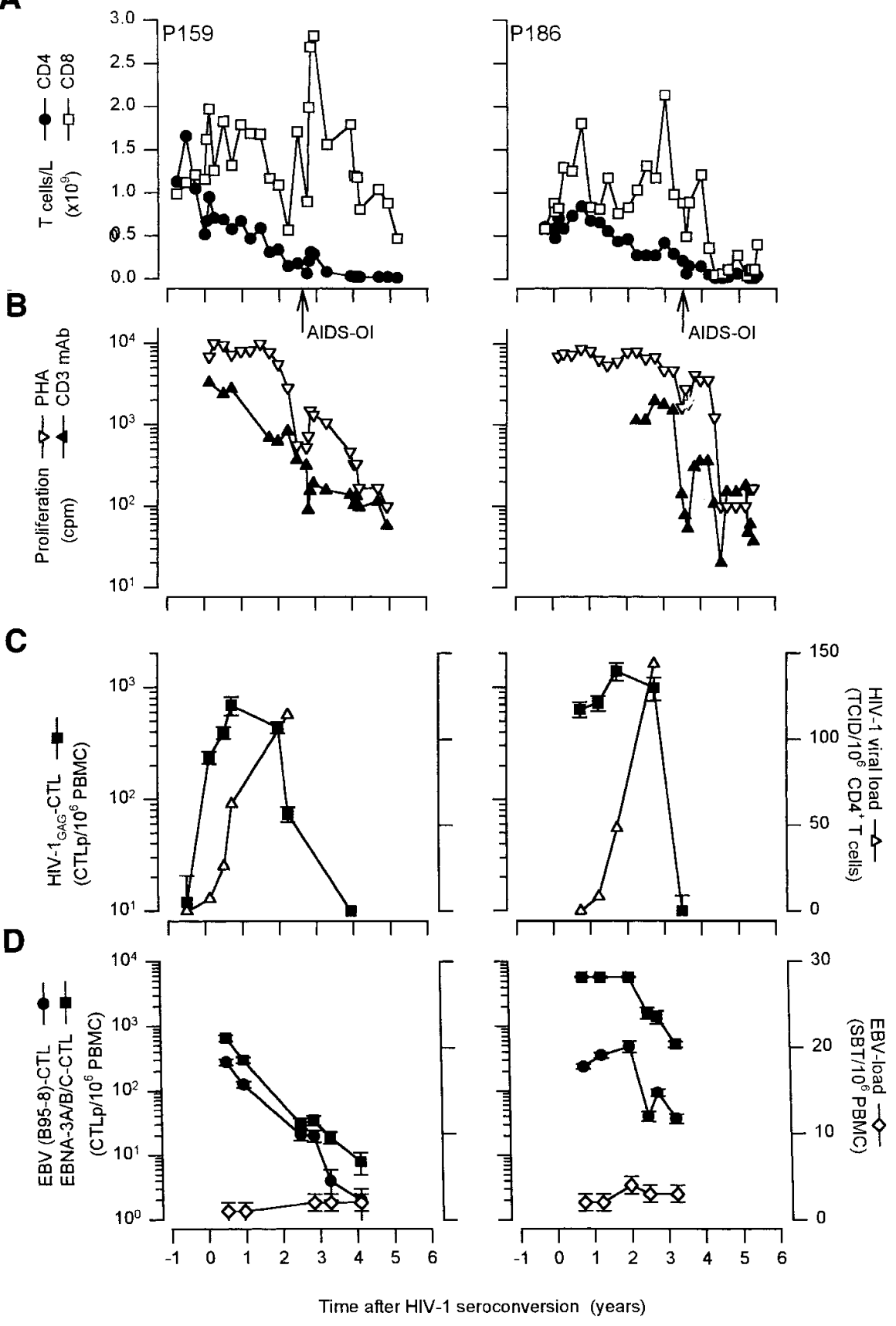

Figure 3. Comparison of HIV-1 and EBVspecific cytotoxic $\mathrm{T}$ lymphocyte responses and viral load in comparison to immune status in two rapid progressors to AIDS. On the $\mathrm{x}$-axis follow up is indicated in years after HIV-1 seroconversion. $(A)$ Longitudinal analysis of CD4 $(\bullet)$ and CD8 $(\square) \mathrm{T}$ lymphocyte subsets. The arrow indicates the time of AIDS-diagnosis. (B) Longitudinal analysis of the $\mathrm{CD} 3 \mathrm{MAb}(\boldsymbol{\Delta})$ and PHA $(\nabla)$-induced $T$ cell reactivity of PBMC measured in real time by a whole blood proliferation assay using $\left[{ }^{3} \mathrm{H}\right]$ thymidine incorporation (expressed as counts per minute [cpm]. $(C)$ Longitudinal analysis of HIV-1 Gag-specific CTLp frequency (ם) analyzed in cryopreserved blood samples (expressed as number of CTLp per $10^{6}$ $\mathrm{PBMC} \pm$ SEM; left axis). Antigen-specific CTL were cultured in limiting dilution and tested in a ${ }^{51} \mathrm{Cr}$ release assay. The HIVload $(\triangle)$ is expressed as tissue culture infectious dose (TCID $/ 10^{6} \mathrm{CD} 4^{+} \mathrm{T}$ cells), representing the proportion of $\mathrm{CD}^{+}$ $\mathrm{T}$ cells productively infected with HIV-1 (right axis). (D) Longitudinal analysis of the EBV-specific $\mathrm{T}$ cell response, using two different targets. (๑) EBV-specific CTLp frequency using B95-8 transformed autologous B-LCL, expressed as number of CTLp per $10^{6} \mathrm{PBMC}$; (ם) EBV-specific CTLp frequency using autologous B-LCL superinfected with $\mathrm{rVV}$ EBNA $3 \mathrm{~A} / \mathrm{B} / \mathrm{C}$ as targets (left axis). The EBV load $(\diamond)$ was estimated with a spontaneous B cell transformation assay (number of EBV-positive $\mathrm{B}$ cells per $10^{6} \mathrm{PBMC}$; right axis). 
low at all time-points studied (Fig. $1 C$ ). In these two subjects, EBV-specific CTLp frequencies remained stable over time (29-156/106 PBMC), and were comparable to the frequencies we found in the healthy controls (4-167/10 ${ }^{6}$ PBMC). EBV load was significantly higher in the LTA than in the blood bank donors (Fig. $1 D ; 2-3$ versus $\leq 1 / 10^{6}$ PBMC, $P=0.003$ ).

Progressors to AIDS. The four progressors included in this study presented with opportunistic infections (Pneumocystis carinii pneumonia or Candida oesophagitis) or Kaposi's sarcoma within $5.5 \mathrm{yr}$ after seroconversion. None of these progressors had EBV-related disease such as oral hairy leukoplakia or NHL. In these patients, a gradual decline in CD4 cell counts to below $0.1 \times 10^{9} /$ liter was paralleled by decreasing polyclonal T cell proliferation (Fig. 2, $A$ and $B$, Fig. 3, $A$ and $B$ ).

As reported before, HIV-1-load steadily increased in all four progressors, despite strong and mounting HIV-1-specific CTL responses early in infection in subjects P159 and P186 (peak CTLp frequencies in these subjects were 691 and 1,386/ $10^{6}$ PBMC respectively; Fig. $3 C$ ). In subject P224 the maximum HIV-1-specific CTLp frequency was relatively low (141/ $10^{6} \mathrm{PBMC}$ ), and in patient $\mathrm{P} 450$ we were never able to detect any Gag-specific CTLp at 10 different timepoints tested. To test whether this latter patient was unable to mount a cellular immune response against HIV-1 at all, CTL reactivity to other HIV-1 antigens including nef, env, and RT was measured. A very low or no CTLp frequency could be detected against nef and env (data not shown). However, a relatively high CTLp frequency $\left(822 / 10^{6} \mathrm{PBMC}\right)$ specific for the RT protein was detected 48 mo after seroconversion. (Fig. $2 C$, subject P450). Eventually during progression to AIDS in the four symptomatic progressors Gag-(or RT)-specific CTL responses were lost.

In all four progressors EBV load was increased approximately fourfold as compared to the healthy controls (mean \pm SD $4.0 \pm 1.1 / 10^{6}$ PBMC; $P=0.01$ ); however the load did not increase further during progression to AIDS. EBVspecific CTLp frequencies were preserved in two out of four progressors (P224 and P450), even though these patients had severely decreased CD4 cell counts, diminished polyclonal T cell reactivity in vitro, and low-to-absent HIV-1-specific CTL responses. In the two patients however who progressed very rapidly to AIDS (P159 and P186; within 32 and 42 mo after seroconversion respectively), EBV-specific CTLp decreased in parallel with the CD3 MAb-induced T cell proliferation in vitro and with HIV-1-specific CTLp frequencies, although in P186

A
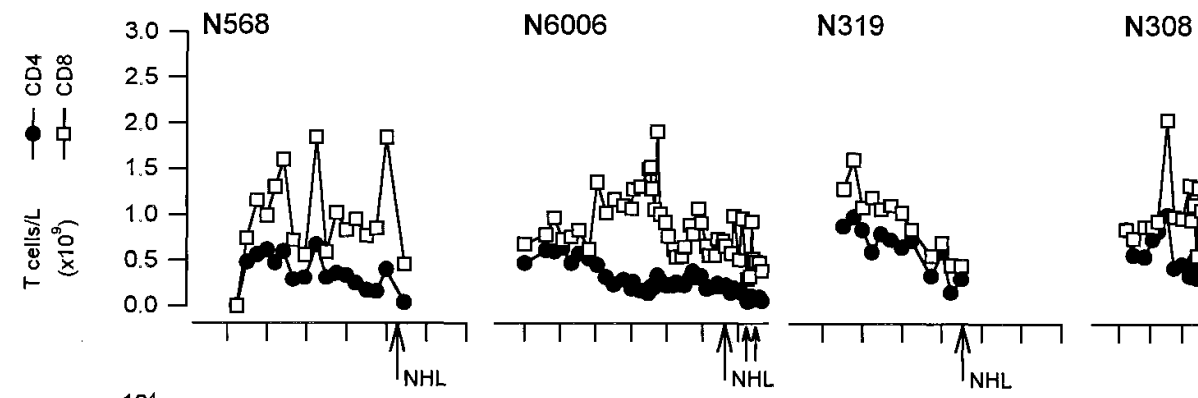

N219

B
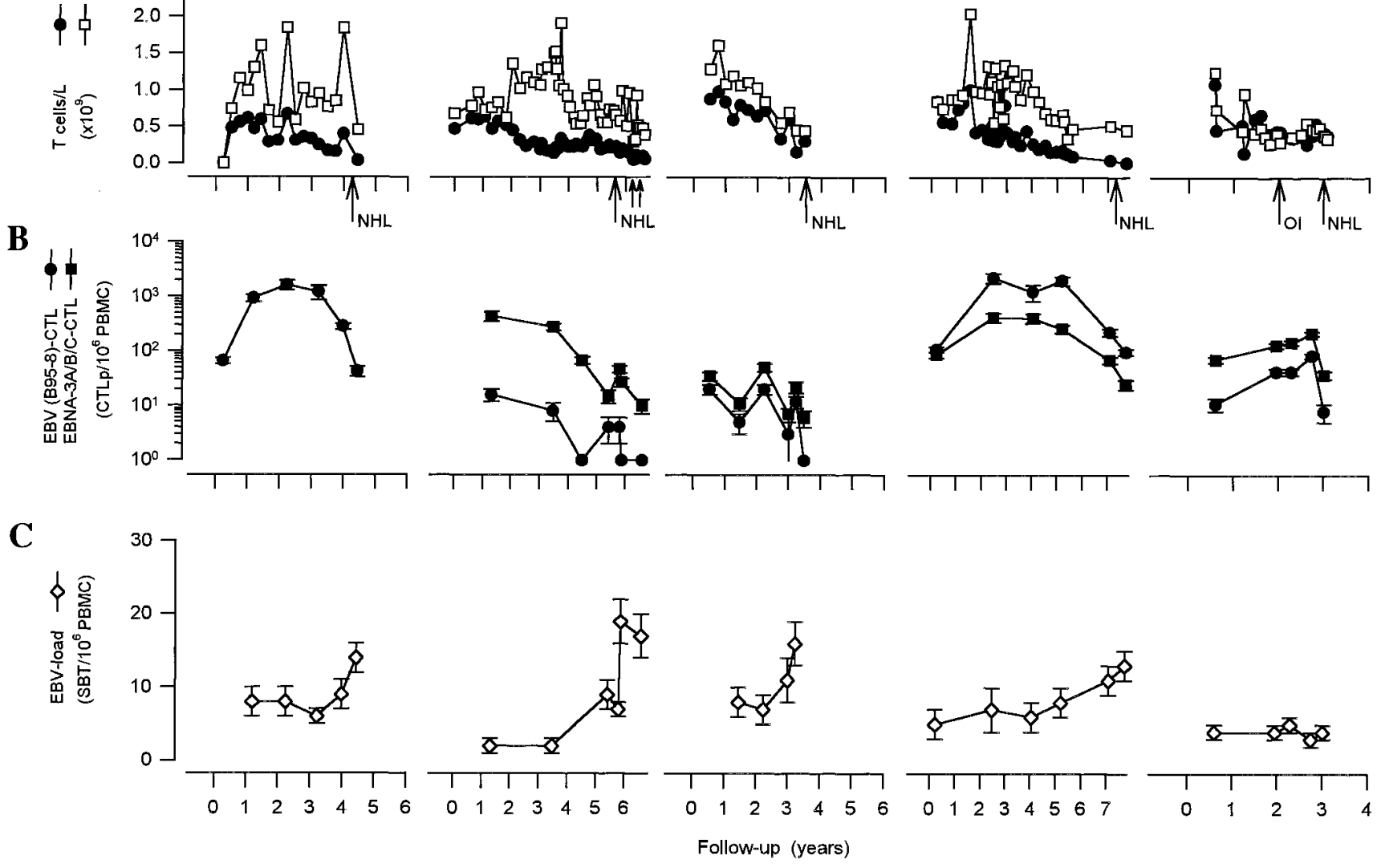

Figure 4. EBV-specific cytotoxic T lymphocyte responses and viral load in comparison to immune status in five patients with diffuse large cell NHL. On the $x$-axis follow up is indicated in years after HIV-1 seropositive entry in the study. $(A)$ Longitudinal analysis of CD4 (•) and CD8 $(\square)$ T lymphocyte subsets. The arrow indicates the time of AIDS-diagnosis. $(B)$ Longitudinal analysis of the EBV-specific T cell response, using two different targets. (-) EBV-specific CTLp frequency using B95-8 transformed autologous B-LCL, expressed as number of CTLp per 10 PBMC; (ם) EBV-specific CTLp frequency using autologous B-LCL superinfected with rVV EBNA 3A/B/C as targets. $(C)$ The EBV load $(\diamond)$ was estimated with a spontaneous B cell transformation assay (number of EBV-positive B cells per $10^{6} \mathrm{PBMC}$ ). 
some residual EBV-specific CTLp (37/106 PBMC) activity was sustained (Fig. $3 \mathrm{D}$ ).

Kinetics of EBV-specific CTLp in patients with AIDS-related diffuse large cell NHL and Burkitt's lymphoma

In four of the five patients with diffuse large cell lymphoma (DLCL), NHL was the AIDS-indicator diagnosis. One patient already had AIDS diagnosed because of Candida oesophagitis one year before NHL occurred. The $\mathrm{CD}^{+} \mathrm{T}$ cell count at NHL diagnosis varied between 0.07 and $0.39 \times 10^{6} / 1$. Patient N6006 had enrolled in an antiretroviral treatment protocol with triple therapy (zidovudine, DDC, and 3TC). In this patient an increase in CD4 cell count and improvement in T cell function after start of antiretroviral treatment was seen. This patient had an unusual disease course: the first biopsy-proven manifestation of high-grade B cell NHL in a subcutaneous lesion on the leg resolved spontaneously without any treatment. After 6 mo the swelling recurred, to disappear again within 4 wk. 5 mo later however he had progressive disease which was unresponsive to chemotherapy.

Four of the five patients had high and increasing EBV load as compared to the healthy controls and to the progressors to AIDS with opportunistic infections $(13.4 \pm 2.3$ vs. $0.7 \pm 0.12$ vs. $4.0 \pm 1.1 / 10^{6}$ PBMC; $P=0.0006$ and 0.008 , respectively). EBVspecific CTLp frequencies were readily detectable in all patients and increased in two patients (N308 and N568) in the first years after seroconversion. EBV-specific CTLp had decreased to low or undetectable levels in all five patients at the time of NHL diagnosis. The decrease in CTLp was especially striking when final CTLp were compared with maximum CTLp frequencies (N308: decrease from 410 CTLp/10 6 PBMC to $25 ; \mathrm{N} 31920$ to 0 ; N568 1,627 to 43; N6006 16 to 0 ; N219 85 to 8 CTLp). The spontaneous remissions of the NHL in subject N6006 seemed to correlate with a temporary increase in EBVspecific CTLp frequencies, which had dropped to undetectable levels before the first appearance of the NHL (Fig. $4 B$ ).

In the two patients with EBV-negative Burkitt-type NHL,
EBV load was comparable to that found in the progressors to AIDS with opportunistic infection (3 and 6/106 PBMC; $P>$ 0.1). EBV-specific CTLp frequencies were low but stable in these patients, who still had relatively high CD4 cell counts and preserved in vitro $\mathrm{T}$ cell reactivity at the time of NHL diagnosis $\left(0.46\right.$ and $1.11 \times 10^{9} /$ liter; Fig. $\left.5 \mathrm{~A}\right)$.

\section{Discussion}

The increased incidence of NHL in HIV-1 infection is believed to be due to failing immune control by EBV-specific CTL because of a general state of cellular immune deficiency induced by HIV-1. Thus far, few data pertinent to this question are available. Some data obtained in transsectional studies are in agreement with this idea, showing low EBV-specific CTL activity in patients with AIDS (9), whereas other studies showed sustained EBV-specific CTL responses with declining HIV1-specific CTLp in advanced HIV-1 infection (10, 11). These latter studies did not include patients that had developed AIDS-NHL, however, and thus it is not clear whether this preservation of EBV-specific immunity is characteristic for patients that do not progress to NHL. One could hypothesize that in NHL patients the EBV specific responses have collapsed as has been shown for HIV-1-specific CTL in patients progressing to AIDS (12). In this study we addressed both these issues by a longitudinal approach taking advantage of a prospective long-term cohort study in homosexual men at risk for HIV-1 infection and AIDS.

Comparison of the kinetics of HIV-1 and EBV-specific CTL responses revealed two distinct patterns: either HIV1- and EBV-specific CTLp showed similar kinetics, or EBVspecific CTLp were maintained longer than HIV-1-specific CTLp. In two very rapid progressors to AIDS (P159 and P186), EBV-specific CTLp decreased in parallel with HIV1-specific CTLp and polyclonal T cell function, although in one of these patients (P186) some residual EBV-specific CTLp

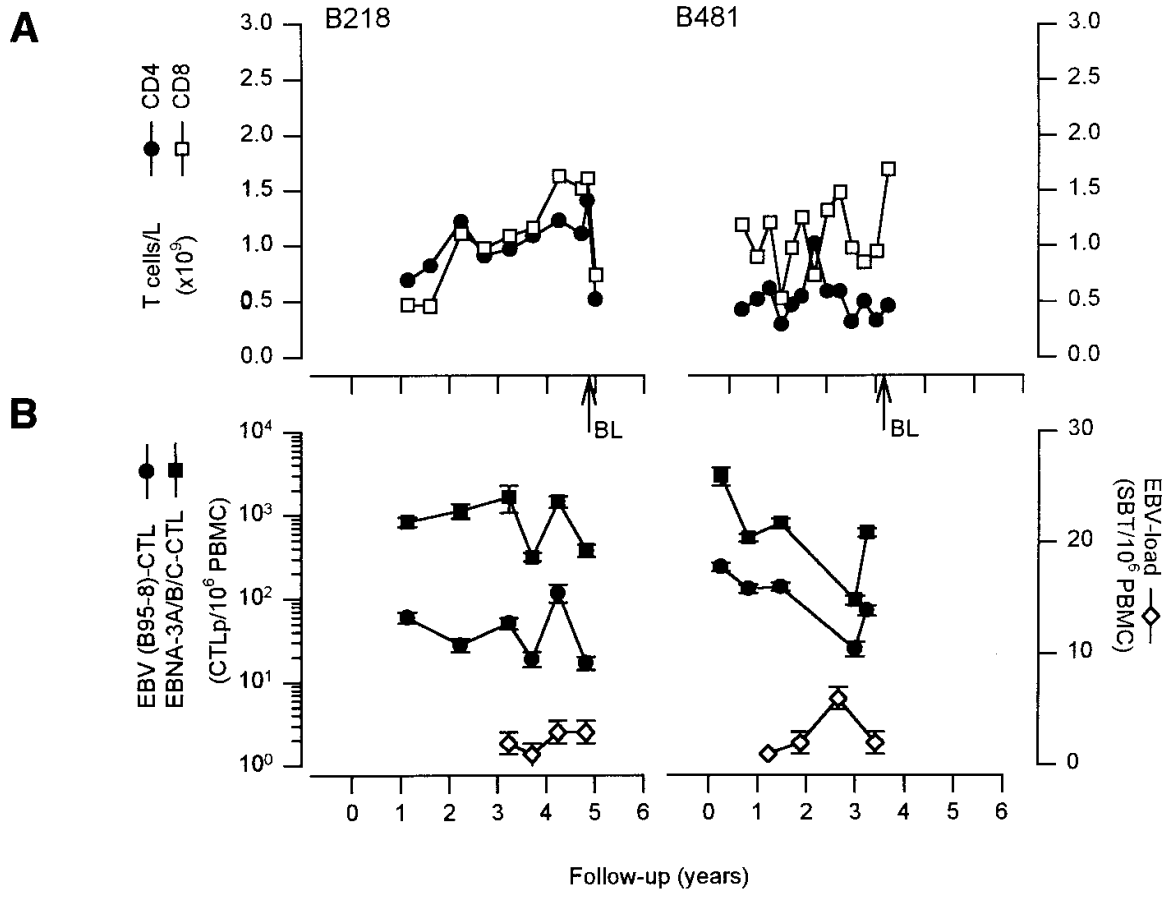

Figure 5. EBV-specific cytotoxic T lymphocyte responses and viral load in comparison to immune status in two patients with Burkitt-type NHL. On the $x$-axis follow up is indicated in years after HIV-1 seropositive entry in the study. $(A)$ Longitudinal analysis of CD4 (๑) and CD8 ( $\square)$ $\mathrm{T}$ lymphocyte subsets. The arrow indicates the time of AIDS-diagnosis. (B) Longitudinal analysis of the EBV-specific T cell response, using two different targets. ( EBV-specific CTLp frequency using B95-8 transformed autologous B-LCL, expressed as number of CTLp per $10^{6}$ PBMC; ( $\left.\mathbf{\square}\right)$ EBV-specific CTLp frequency using autologous B-LCL superinfected with rVV EBNA $3 \mathrm{~A} / \mathrm{B} / \mathrm{C}$ as targets (left axis). The EBV load $(\diamond)$ was estimated with a spontaneous $B$ cell transformation assay (number of EBV-positive B cells per $10^{6} \mathrm{PBMC}$; right axis). 
activity was measured. In contrast, in both LTA and in two typical progressors (L120, L206, P224, and P450), HIV-specific CTLp decreased over time whereas EBV-specific CTLp were preserved. EBV-CTLp were detectable despite very low CD4 counts of $0.01 \times 10^{9} /$ liter and severely depressed in vitro $\mathrm{T}$ cell reactivity in the two progressors. Although also in the longterm asymptomatic infected individuals a decline in HIV1-specific CTLp was observed, they apparently still had adequate control over the virus as reflected by very low to undetectable virus load. Whether or not they are true LTA will have to be determined by longer follow up. In P159, HIV-1 viral load was shown to increase soon after seroconversion, despite a strong and mounting CTL response. This could indicate the emergence of viral escape mutants. Before AIDS diagnosis also in this patient HIV-CTLp collapsed.

Our results show, therefore, that in HIV-1-infected individuals, the perturbation of the immune system did not invariably cause a simultaneous decline of the immune response directed against these two persistent viruses. Only in the very rapid progressors to AIDS was the complete loss of $\mathrm{T}$ cell function and a simultaneous rapid decline of HIV-1- and EBV-specific CTLp observed, indicative for total collapse of cellular immunity. The difference in HIV-1- and EBV-specific CTLp kinetics may point to a selective or earlier impairment of the HIV-1-specific CTL response, especially in the patients that progress less rapidly to AIDS. There are several possible explanations for this phenomenon. The first possibility is clonal exhaustion of HIV-1-specific CTLp due to chronic immune activation with continuously high levels of virus, as has been demonstrated in a mouse model with lymphocytic choriomeningitis virus (23). This is supported by recent elegant studies in HIV-1-infected patients treated with very potent antiretroviral drugs that showed extremely rapid turnover of virus and virus-infected cells $(24,25)$. Second, it has been demonstrated in vitro that there is a differential requirement for $\mathrm{CD}^{+} \mathrm{T}$ cell help between HIV-1- and EBV-specific CTL. Whereas EBV-specific CTL can be efficiently generated in the absence of $\mathrm{CD}_{4}^{+} \mathrm{T}$ cells and exogenous rIL-2, HIV-1-specific CTL cannot be induced under such conditions $(26,27)$. However, because in both virus-specific CTL assays ample amounts of rIL-2 are added this may not be a likely explanation. There could also be a difference in the need for other cytokines essential for the activation and differentiation of CTL (for example IL-7, IL-12, and/or IL-15), or the sensitivity to inhibitory cytokines which cause nonresponsiveness at the effector cell level (e.g., IL-10) (28). Future studies could be aimed at the exact requirements of HIV-1- and EBV-specific T cells (for example using different combinations of stimulatory and inhibitory cytokines or cytokine-directed monoclonal antibodies) to explain these differences. Given the recent insights in the dynamics of HIV-1 infection, exhaustion of HIV-1-specific CTL responses may be the more likely explanation. It is now clear that during clinical latency of HIV-1 infection a high level of virus turnover occurs, which may be in the order of $10^{10}$ viral RNA copies produced and cleared per day, in many cases for more than 5 to $10 \mathrm{yr}$ in a row (24). Moreover it has been shown that productively infected cells are quickly turning over with a half life averaging $2 \mathrm{~d}$. This huge number of viruses and infected cells induces a vigorous and chronic immune activation, in part specific for HIV-1 but also involving a lot of CD $8^{+} \mathrm{T}$ cell bystander activation that is reflected in high levels of $\mathrm{CD}^{+}$and $\mathrm{CD} 8^{+} \mathrm{T}$ cell apoptosis (29). Thus, in patients pro- gressing relatively slowly to AIDS, HIV-1-specific CTL may have been extensively utilized compared to CTL with specificities to other persistent but less prolific viruses. It might be of interest to see whether this dichotomy in later stage HIV-1 infection can also be found for CTL specific for cytomegalovirus or varicella zoster virus.

In the patients that developed NHL EBV-CTLp, frequencies early in HIV-1 infection were comparable to those seen in AIDS opportunistic infection (OI) patients. They were shown to increase in some of the patients, possibly in response to increasing EBV-load. However, in the 24 mo before NHL was diagnosed, EBV-CTLp in the peripheral blood decreased rapidly in the NHL patients. This drop in CTLp was accompanied by a rise in EBV load in four of the five NHL patients to levels more than 10-fold higher than in the AIDS-OI patients. It could be argued that the drop of CTLp in the circulation might be due to massive homing of CTL to the affected lymphoma sites, but given the very low numbers of $\mathrm{T}$ cells usually found in biopsies of AIDS-related NHL, this is not likely.

The data thus suggest that it is not merely the decreased EBV-specific CTL response, but rather the balance between EBV load and CTL that allows for the occurrence of NHL. The pathogenesis of AIDS-NHL is probably multifactorial, and it takes time for virus-infected B cells to acquire genetic hits that result for example in oncogene (c-myc) activation and thus to develop into transformed malignant $B$ cells. It is likely that viral (transforming) properties of EBV, next to absolute CTL levels and rate of decline, determine the pace of this process. Although CTLp were very low in patient P159, the rapid progression to AIDS-OI may not have allowed for enough time for NHL to develop. Because in the patients with EBVnegative Burkitt-type NHL, EBV-specific CTL remained detectable and EBV load was comparable to that found in the progressors to opportunistic infection, it is unlikely that having NHL itself influenced our results.

AIDS-related NHL has a very dismal prognosis with a median survival after diagnosis of only 3-6 mo $(30,31)$. Because treatment with either conventional or high-dose chemotherapy yields very poor results and is associated with high morbidity in this patient group, it has been suggested that patients with AIDS-related NHL could, in analogy to patients with posttransplant lymphoproliferative disease (PTLD; 32, 33), be candidates for treatment with in vitro expanded EBV-specific CTL. In our hands, in the limited patient group we were able to study in detail, increasing EBV load correlated strongly with subsequent progression to NHL. Our findings suggest therefore that, as in patients with posttransplant lymphoproliferative disease, defective EBV-immunosurveillance does indeed play a role in the pathogenesis of AIDS-related diffuse large cell NHL. Further studies seem warranted to investigate whether treatment of patients with AIDS-related NHL or even already those with increasing EBV-load (34) with in vitro expanded CTL or with CTL-activating cytokines is a rational approach.

\section{Acknowledgments}

We thank M. Roos, A. Hekman, N. Pakker, S. Kerkhof-Garde, and O. Pontesilli for expert technical assistance, and H. Schuitemaker and R.A.W. van Lier for critically reading the manuscript.

This study was performed as part of the Amsterdam Cohort Studies on AIDS, a collaboration between the Municipal Health Service (R. Coutinho), the Academic Medical Center (J. Goudsmit and 
J.M.A. Lange), and the Central Laboratory of the Netherlands Red Cross Blood Transfusion Service (F. Miedema), Amsterdam, The Netherlands. The authors are grateful for the continuous participation of the cohort participants. Clinical data on the cohort participants were provided by I.P.M. Keet and J. Veenstra. Recombinant vaccinia viruses were kindly provided by Dr. Y. Rivière, Dr. M.P. Kieny, and Dr. A.B. Rickinson. This study was financially supported by the Dutch Cancer Society and by the Dutch AIDS foundation.

\section{References}

1. Miller, G. 1990. Epstein-Barr virus: biology, pathogenesis, and medical aspects. In Virology. 2nd ed. B.N. Fields, D.M. Knipe, editors. Raven Press, New York. 1921-1958.

2. Rickinson, A.B. 1990. Cellular immunological responses to the virus infection. In The Epstein-Barr Virus: Recent Advances. M.A. Epstein, B.G. Achong, editors. John Wiley \& Sons, New York. 75-115.

3. Purtilo, D.T., R.S. Strobach, M. Okano, and J.R. Davis. 1992. EpsteinBarr virus-associated lymphoproliferative disorders. Lab. Invest. 67:5-23.

4. Cohen, J.I. 1991. Epstein-Barr virus lymphoproliferative disease associated with acquired immunodeficiency. Medicine (Baltimore). 70:137-160.

5. Shibata, D., L. Weiss, A. Hernandez, B. Nathwani, L. Bernstein, and A.A.M. Levine. 1993. Epstein-Barr virus-associated non-Hodgkin's lymphoma in patients infected with the human immunodeficiency virus. Blood. 81:21022109.

6. McClain, K.L., C.T. Leach, H.B. Jenson, V.V. Joshi, B.H. Pollock, R.T. Parmley, F.J. Dicarlo, E. Gould Chadwick, and S.B. Murphy. 1995. Association of Epstein-Barr virus with leiomyosarcomas in young people with AIDS. $N$. Engl. J. Med. 332:12-18.

7. Hamilton-Dutoit, S.J., G. Pallesen, and M.B. Franzmann. 1991. AIDSrelated lymphoma. Histopathology, immunophenotype and association with Epstein-Barr virus, as demonstrated by in situ hybridisation. Am. J. Pathol. 138: 149-163.

8. Birx, D.L., R.R. Redfield, and G. Tosato. 1986. Defective regulation of Epstein-Barr virus infection in patients with acquired immunodeficiency syndrome (AIDS) or AIDS-related disorders. N. Engl. J. Med. 314:874-879.

9. Blumberg, R.S., T. Paradis, R. Byington, W. Henle, M.S. Hirsch, and R.T. Schooley. 1987. Effects of Human Immunodeficiency Virus on the cellular immune response to Epstein-Barr Virus in homosexual men: characterization of the cytotoxic response and lymphokine production. J. Infect. Dis. 155:877890.

10. Carmichael, A., X. Jin, P. Sissons, and L. Borysiewicz. 1993. Quantitative analysis of the human immunodeficiency virus type 1 (HIV-1)-specific cytotoxic T lymphocyte (CTL) response at different stages of HIV-1 infection: differential CTL response to HIV-1 and Epstein-Barr virus in late disease. $J$. Exp. Med. 177:249-256.

11. Geretti, A.M., M.E.M. Dings, C.A.C.M. van Els, C.A. van Baalen, F.J. Wijnholds, J.C.C. Borleffs, and A.D.M.E. Osterhaus. 1996. Human immunodeficiency virus type 1 (HIV-1)- and Epstein-Barr Virus-specific T lymphocyte precursors exhibit different kinetics in HIV-1-infected persons. J. Infect. Dis. $174: 34-45$

12. Klein, M.R., C. van Baalen, A.M. Holwerda, S.R. Kerkhof Garde, R.J. Bende, I.P.M. Keet, J.K.M. Eeftinck Schattenkerk, A.D.M.E. Osterhaus, H. Schuitemaker, and F. Miedema. 1995. Kinetics of gag-specific cytotoxic T lymphocyte responses during the clinical course of HIV-1 infection: a longitudinal analysis of rapid progressors and long-term asymptomatics. J. Exp. Med. 181: 1365-1372.

13. Schellekens, P.T.A., M.T.L. Roos, F. de Wolf, J.M.A. Lange, and F. Miedema. 1990. Low T-cell responsiveness to activation via CD3/TCR is a prognostic marker for AIDS in HIV-1 infected men. J. Clin. Immunol. 10:121127.

14. Rautmann, G., M.P. Kieny, R. Brandely, K. Dott, M. Girard, L. Montagnier, and J.P. Lecocq. 1989. HIV-1 core proteins expressed from recombinant vaccinia viruses. AIDS Res. Hum. Retroviruses. 5:147-157.
15. van Baalen, C.A., M.R. Klein, A.M. Geretti, I.P.M. Keet, F. Miedema, C.A.C.M. van Els, and A.D.M.E. Osterhaus. 1993. Selective in vitro expansion of HLA class I-restricted HIV-1 gag specific CD ${ }^{+} \mathrm{T}$ cells from seropositive individuals: Identification of CTL epitopes and precursor frequencies. AIDS (Philadelphia). 7:781-786.

16. Lefkovits, I., and H. Waldmann. 1979. Poison distribution. In Limiting Dilution Analysis of Cells in the Immune System. Cambridge University Press, Cambridge. 38-59.

17. Bourgault, I., A. Gomez, E. Gomard, and J.P. Levy. 1991. Limiting dilution analysis of the HLA restriction of anti-Epstein Barr virus-specific cytolytic T lymphocytes. Clin. Exp. Immunol. 84:501-507.

18. Strijbosch, L.W.G., W.A. Buurman, R.J.M.M. Does, P.H. Zinken, and G. Groenewegen. 1987. Limiting dilution assays. Experimental design and statistical analysis. J. Immmunol. Methods. 97:133-140.

19. Khanna, R., S.R. Burrows, M.G. Kurilla, C.A. Jacob, I.S. Misko, T.B. Sculley, E. Kieff, and D.J. Moss. 1992. Localization of Epstein-Barr virus cytotoxic T cell epitopes using recombinant vaccinia: implications for vaccine development. J. Exp. Med. 176:169-176.

20. Schuitemaker, H., M. Koot, N.A. Kootstra, M.W. Dercksen, R.E.Y. de Goede, R.P. van Steenwijk, J.M.A. Lange, J.K.M. Eeftinck Schattenkerk, F. Miedema, and M. Tersmette. 1992. Biological phenotype of human immunodeficiency virus type 1 clones at different stages of infection: progression of disease is associated with a shift from monocytotropic to T cell-tropic virus populations. J. Virol. 66:1354-1360.

21. Thorley-Lawson, D.A., L. Chess, and J.L. Strominger. 1977. Suppression of in vitro Epstein-Barr virus infection. J. Exp. Med. 146:495-508.

22. Yao, Q.Y., P. Ogan, M. Rowe, M. Wood, A.B. Rickinson. 1989. Epstein-Barr virus-infected $\mathrm{B}$ cells persist in the circulation of acyclovir-treated virus carriers. Int. J. Cancer. 43:67-71.

23. Moskophidis, D., F. Lechner, H. Pircher, and R.M. Zinkernagel. 1993. Virus persistence in acutely infected immunocompetent mice by exhaustion of antiviral cytotoxic effector T cells. Nature (Lond.). 362:758-761.

24. Ho, D.D., A.U. Neumann, A.S. Perelson, W. Chen, J.M. Leonard, and M. Markowitz. 1995. Rapid turnover of plasma virions and CD4 lymphocytes in HIV-1 infection. Nature (Lond.). 373:123-126.

25. Wei, X., S.K. Ghosh, M.E. Taylor, V.A. Johnson, E.A. Emini, P. Deutsch, J.D. Lifson, S. Bonhoeffer, M.A. Nowak, B.H. Hahn et al. 1995. Viral dynamics in human immunodeficiency virus type 1 infection. Nature (Lond.). 373:117122

26. Fishwild, D.M., C.J. Benike, and E.G. Engleman. 1988. Activation of HLA-restricted EBV-specific cytotoxic T cells does not require CD4+ (helper) T cells or exogenous cytokines. J. Immunol. 140:1994-1998.

27. Jin, X., A.J. Carmichael, M. Wills, and J.G.P. Sissons. 1994. Differential requirement of $\mathrm{CD}^{+}{ }^{+} \mathrm{T}$ helper cells in generating EBV and HIV specific CTL responses. Proc. Eur. Immunol. Meet., 12th, Barcelona. 470(Abstr.).

28. Matsuda, M., F. Salazar, M. Petersson, G. Masucci, J. Hansson, P. Pisa, Q.J. Zhang, M.G. Masucci, and R. Kiessling. 1994. Interleukin 10 pretreatment protects target cells from tumor- and allo-specific cytotoxic T cells and downregulates HLA Class I expression. J. Exp. Med. 180:2371-2376.

29. Meyaard, L., S.A. Otto, R.R. Jonker, M.J. Mijnster, I.P.M. Keet, and F. Miedema. 1992. Programmed death of T cells in HIV-1 infection. Science (Wash. DC). 257:217-219.

30. Levine, A.M. 1992. Acquired immunodeficiency syndrome related lymphoma. Blood. 80:8-20.

31. Northfelt, D.W., and L.D. Kaplan. 1991. Clinical manifestations and treatment of HIV-related non-Hodgkin's lymphoma. Cancer Surv. 10:121-133.

32. Rooney, C.M., C.A. Smith, C.Y.C. Ng, S. Loftin, C. Li, R.A. Krance, M.K. Brenner, and H.E. Heslop. 1995. Use of gene-modified virus-specific T lymphocytes to control Epstein-Barr-virus-related lymphoproliferation. Lancet. 345:9-13.

33. Papadopoulos, E.B., M. Ladanyi, and D. Emanuel. 1994. Infusions of donor leukocytes to treat Epstein-Barr virus lymphoproliferative disorders after allogeneic bone marrow transplantation. N. Engl. J. Med. 330:1185-1191.

34. Savoie, A., C. Perpete, L. Carpentier, J. Joncas, and C. Alfieri. 1994. Direct correlation between the load of Epstein-Barr virus-infected lymphocytes in the peripheral blood of pediatric transplant patients and risk of lymphoproliferative disease. Blood. 83:2715-2722. 